\title{
Evolution of Human Factors Research and Studies of Health Information Technologies: The Role of Patient Safety
}

\author{
M.C. Beuscart-Zéphir', E. Borycki², P. Carayon ${ }^{3}$, M.W.M. Jaspers ${ }^{4}$, S. Pelayo ${ }^{1}$ \\ I INSERM CIC-IT/Evalab, Lille; CHU Lille; Université Lille Nord de France, UDSL EA 2694; Lille, France \\ ${ }^{2}$ School of Health Information Science, University of Victoria, Victoria, British Columbia, Canada \\ ${ }^{3}$ Department of Industrial and Systems Engineering, Center for Quality and Productivity \\ Improvement, University of Wisconsin-Madison, Madison, Wisconsin, USA \\ ${ }^{4}$ Center of Human Factors Engineering of Health Information Technology, Department of Medical \\ Informatics, Academic Medical Center, University of Amsterdam, The Netherlands
}

\begin{abstract}
Summary
Objectives: The objective of this survey paper is to present and explain the impact of recent regulations and patient safety initiatives (EU, US and Canada) on Human Factors (HF)/Usability studies and research focusing on Health Information Technology (HIT).

Methods: The authors have selected the most prominent of these recent regulations and initiatives, which rely on validated $\mathrm{HF}$ and usability methods and concepts and aim at enhancing the specific process of identification and prevention of technology-induced errors throughout the lifecycle of HIT.

Results: The analysis highlights several points of consensus: 1) safety initiatives or regulations applicable to Medical Devices (MD) tend to extend to HIT, 2) Usability is considered a fundamental dimension of HIT safety, 3) HF/Usability methods and the overall Human Centred Design (HCD) approach are considered efficient solutions to ensure the design of safe and usable HIT. However, it appears that MD manufacturers, and a fortiori HIT designers and developers are still far from being able to routinely apply HCD to their products

Discussion and conclusion: On the research side, we need to analyze manufacturers' difficulties with the application of the HCD process and imposed standards. For each given category of HIT, we need to identify the fundamental usability dimensions and design principles likely to impact patient safety independently of workplace settings or organizations. These should be described in terms of usability flaws, corresponding usage problems experienced by users and related outcomes. This approach requires good quality and well structured reporting of Human Factors / Usability research studies on HIT.
\end{abstract}

\section{Keywords}

Human engineering, usability, patient safety, regulation, medical informatics applications

Yearb Med Inform 2013:67-77

\section{Introduction}

Human Factors (HF) is an important area of health informatics research. Over the past several years, research studies have reported that poorly designed and implemented Health Information Technology (HIT) may negatively influence the process of patient care, clinician workflows and health professional work activities as well as introduce technology-induced errors. Increasingly, we have seen governments' and international bodies' attempt to address these issues through investment in further analysis and regulation of systems.

The objective of this survey paper is to present and illustrate the impact of recent regulations and patient safety initiatives on HF studies and research in the area of HIT systems. Awareness of the role of HF issues in the success or failure of HIT applications has been growing steadily over the past two decades. In parallel, we have observed the progressive emergence and organization of the corresponding research field, i.e. Human Factors (or Ergonomics) as applied to Health Informatics, the organization of experts in the domain, and the development of knowledge in the form of guidelines and recommendations for the design and implementation of usable and safe HIT products. HF expertise is applied through Human Factors Engineering at all stages of HIT projects, including the $[1,2]$ :

- Design and development of products

- Implementation of products in the clinical setting and all related activities, including parameterization and organizational design of the work system in which products are to be implemented

The present survey paper limits its scope to the first category of tasks, i.e. the design (or re-design) and development of HIT applications and the corresponding Human Factors activities usually referred to as "usability".

Since the publication of the IOM report "To Err is Human" [3], prevention of medical errors has been a strategic activity for healthcare organizations and institutions at the national and international level. Health information systems and applications have been considered promising tools to enhance safety of healthcare systems and processes; therefore, a wide range of incentives throughout the developed $[4,5]$ and developing countries [6] have emerged. This high expectation underlines the need for increased attention to observations and evidence that some HIT products may not only fail to prevent known medical errors but may also contribute to the emergence of new types of errors [7, 8]. Growing concern over medical errors related to the introduction of HIT into clinical settings has arisen and these errors, which are sometimes called "use errors" or "technology-induced errors", have generated a number of initiatives and, more importantly, new regulations applicable to HIT, e.g. the revised European Medical Device Directive [9]. In the past two years, enforcement of these initiatives and regulations have resulted in a notable demand for usability studies of 
HIT and for extended HF research to better prevent use errors / technology-induced errors in healthcare [10-12]. Based on the experience and expertise of the authors, this survey paper summarizes this recent evolution and identifies emerging and persistent research challenges.

\section{Background}

\subsection{Human Factors / Ergonomics and Usability}

According to the International Ergonomics Association, [13] Human Factors or Ergonomics ${ }^{1}$ is "the scientific discipline concerned with the understanding of interactions among humans and other elements of a (work) system, and the profession that applies theory, principles, data and methods to design in order to optimize human well being and overall (work) system performance". Safety is a critical component of system performance.

There are several domains of specialization in Human Factors or Ergonomics, namely Physical Ergonomics, Cognitive Ergonomics and Organizational Ergonomics (or macroergonomics). Various aspects of HIT design and implementation are concerned by these dimensions of HF. Cognitive ergonomics is by far the most important domain of HF for HIT design. It addresses essential aspects of individual and collective healthcare tasks such as decision making, human-computer interaction, mental workload, human reliability and work stress, which are of critical importance for interaction with HIT tools.

HF work and research rely heavily on qualitative methods, which have been progressively structured, organized and standardized into an overall approach referred to as Human-Centered Design - HCD (or User-Centered Design - UCD) [14]. This particular process to system design is iterative in nature and includes several key steps, as illustrated in figure 1 :

\footnotetext{
1 Human Factors and Ergonomics are synonyms and may be used interchangeably.
}

- analysis and understanding of the context of use, which includes the observation and analysis of the work system in which the product is to be implemented, along with a review of existing literature reporting incidents or use errors with similar products

- specification of users' requirements, including the identification of key usability features for the system under design

- design solutions

- iterative evaluation of the usability of design solutions

The process goes on until evaluation demonstrates that the system under development satisfies all specified requirements. In this HCD approach, observation and analysis of existing work systems and their technology is an essential part of HF work. For decades, HF professionals or ergonomists have been observing people at work interacting with all sorts of tools and artifacts. In doing so, ergonomists have progressively identified essential characteristics of these tools that make them more or less easy to use and easy to learn how to use. This is how the concept of "usability" comes into play. Usability is "the extent to which a product can be used by specified users to achieve specified goals with effectiveness, efficiency and satisfaction in a specified context of use" [14]. Usability goes way beyond the features of the
Graphical User Interface (GUI) (e.g. legibility of the texts, layout and prompting of information and tools), and deals more generally with the fit between systems' behavior and users' needs. Considering HIT applications, one of the most important usability features which violations may engender important usage problems and negative outcomes is the compatibility of the system with clinicians' activities, essentially those with a cognitive nature $[15,16]$.

In summary, the contribution of HF/Usability expertise to HIT is twofold:

- the identification of key usability features of various categories of HIT applications or functions that should be considered mandatory design principles to obtain usable and safe systems

- the methodological knowledge to properly implement and eventually adapt the HCD process to HIT systems

\subsection{HIT Usability and Patient Safety Concerns}

HIT systems are designed and implemented in clinical settings to improve the quality of healthcare work and to improve patient, clinical and organizational outcomes, especially where patient safety is concerned [12, 17]. Indeed HIT has the potential to reduce medical errors [3] and has proven to do so

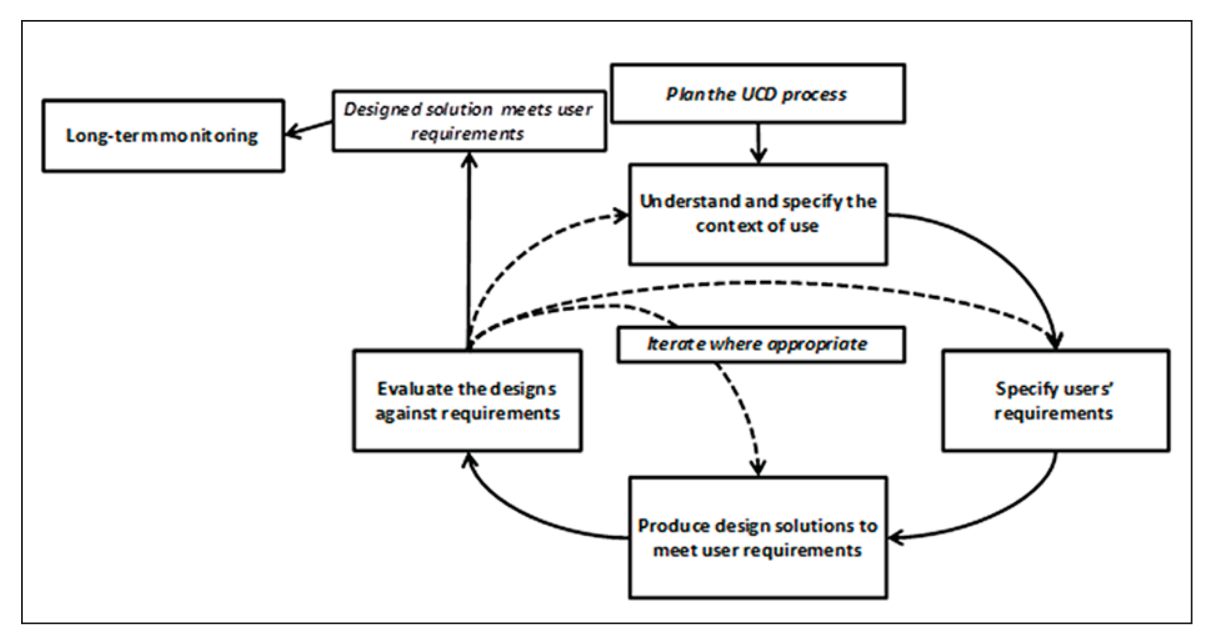

Fig. 1 the Human-Centered Design (HCD) process adapted from the ISO 9241-210:2010 
in some studies [18]. Unfortunately, in spite of continuous progress in HF knowledge, too many HIT systems (including recently developed ones) still suffer from severe usability flaws that make them prone to use errors and potentially dangerous in terms of patient safety. Growing awareness about the potential negative impact of poor usability of the products delivered to healthcare professionals has acted as a powerful leverage to enhance usability studies and more generally to support Human-Centered approaches to the design of HIT applications and systems. The ultimate objective of most initiatives in this domain is to prevent medical errors due to systems' usability flaws, usually referred to as "use errors" [19-21] or "technology-induced errors" [7, 11].

It is acknowledge that software in the healthcare industry can be either safe or unsafe [22]. More importantly, researchers have identified that some software features, functions and workflows either improve or detract HIT's safety and quality $[11,12,23$ 26]. As HIT has the ability to improve the quality and safety of healthcare while at the same time introducing new opportunities for patient harm, injury, disability and death [7, $27,28]$, there is a need to understand features and functions of HIT that lead to improved safety and eliminate those that lead to technology-induced errors [23].

\subsubsection{Use Errors / Technology-induced Errors}

Technology-induced errors are those errors that "arise from: (a) the design and development of a technology, (b) the implementation and customization of a technology, and (c) the interactions that emerge during the operation of a new technology and the new work processes that arise from a technology's use" [23]. Technology-induced errors differ from unintended consequences. Unintended consequences form a broad range of "unexpected results" resulting from a technology's use. They may be classified as either 'desirable" or 'undesirable' [29]. Technology-induced errors are among the many unintended consequences that result from technology's use [23]. Attention to HF throughout the software development lifecycle can prevent many technology-induced errors.
Over the past several years, we have seen a significant rise in the number of reports of such technology-induced errors in both research and popular literature $[8,11,27$, 30]. There are several reasons for this:

- an increase in the number and diversity of HIT systems that are being implemented, as some governments are incentivizing health care organizations and physicians to implement electronic records in countries such as the Canada and the United States [4, 31],

- an increased awareness among healthcare professionals and organizations about the real need to be concerned about these types of errors [11, 32],

- a recognition by governments and vendors that healthcare should expect vendors to provide high quality HIT that supports healthcare work [33, 34], and

- an increased media attention to reports, where HIT systems have led to death or disability [27, 28].

The number of reports of technology-induced errors is growing while at the same time national, provincial and state governments are struggling to find ways of identifying, preventing and addressing them $[35$, $36]$ through industry regulation $[33,37,38]$.

\subsubsection{Examples of Technology-induced Errors that Could be Prevented}

According to the literature, some HIT features and functions have contributed to harm, disability and death. Researchers have noted the importance of documenting examples of technology-induced errors. A review of Australian and U.S. incident reports outlined a number of technology-induced errors [27, 28]. Table 1 provides some examples of technology-induced errors identified from incident reporting databases.

Methods developed by usability and clinical simulation researchers show considerable promise in the identification of technology-induced errors. Researchers have identified specific features and functions of software as well as their emergent workflows as leading to error. Often, the rigid, linear, structured work processes reflected in HIT user interfaces do not adequately address health care professionals' actual work processes, which typically are nonlinear and flexible. Exposure to such systems can affect healthcare providers' information gathering and reasoning strategies [39]. In addition, HIT systems and end users interact in working environments that are very complex. Within these environments, tasks carried out by healthcare professionals are often context-dependent, unpredictable, interrupted, and rely on clear and timely communication between different stakeholders [40]. Introduction of poorly designed HIT into these complex health care environments can cause disruptions in communication among clinicians and may lead to workarounds [4145]. These misfits between HIT designs and workflow processes create new opportunities for new sources of error.

Most of the time, technology-induced errors are identified after a system has been put into use [30] or after life threatening errors have occurred [27, 46]. Such work is important; however, in the future we need to shift from documenting and addressing errors after they have occurred, to preventing their occurrence or mitigating their effects on patient safety at the design stage $[10,11]$. It is worthy to note that HF researchers and usability engineers indeed have the capability to identify the interface design features, functions and emergent workflows that may have error-inducing properties before the system is actually implemented. For example, the evaluation of a prescribing system at the prototype stage [11] noted data entry, display visibility, locating, speed, database content and defaults as error prone features. If not fixed, these usability problems would lead physicians to make errors when using this system.

\section{Table 1 Examples of technology-induced errors from incident reporting databases}

A small font size was used to communicate information. This led to poor display usability. As a result the strength of a medication was not adequately displayed. An overdose of epinephrine occurred and this led to a myocardial infarction in a patient.

The system did not provide medication doses in milligrams. This led to a patient receiving three times the maximum dose of Tylenol-oxycodone (within a 24 hour period). 


\subsubsection{Methods Used to Identify and Prevent Technology-induced Errors}

Internationally, researchers are attempting to develop methods that can be used to identify technology-induced errors. These methods are integrated within the HCD process and can be applied before a system is implemented, following its implementation, during technology optimization or maintenance, or after an error has occurred [11,36, 47] (see Table 2).

Usability testing and clinical simulations have demonstrated their value in relating interface design $[10,35,48]$, the clinical workflows emerging from using a technology and technology-induced errors $[24,49]$. These methods are also very efficient in supporting HIT procurement, and they allow organizations to identify and purchase safe HIT that fit their organizational needs [50]. Ethnographic approaches have been used to identify technology-induced errors after a system has been implemented [43, 51]. Case study approaches and mixed methods have been used to understand the confluence of factors that contribute to technology-induced errors in order to prevent their future occurrence $[8,15]$.

Few published studies have fully explored the application of root cause analysis to develop an enhanced understanding of new and emerging technology-induced errors in healthcare $[8,15,36,52]$. To date, studies have documented the relationship between systems design, knowledge organization, reasoning and decision making [39]. Future research on HF methods and models should be more emphasized. Here researchers need to explore the link between HIT design features, quality of decision-making and errors [39, 53].

\section{Initiatives to Prevent Use Errors and their Impact in Terms of HF Research}

A number of recent national and international initiatives rely on validated $\mathrm{HF}$ and usability methods and concepts to enhance the specific process of identifying and preventing technology-induced errors throughout the lifecycle of HIT [54]. Most of these initiatives address one (or a combination) of the following objectives:

- Require the integration of a standardized (safety-oriented) HCD process during the design and development of HIT products, and try to control and normalize the HCD process.

- Example: European revised Medical Device Directive (MDD) [9] and

Table 2 Possible set of methods that can be used to prevent technology induced errors

\begin{tabular}{|l|l|}
\hline Stage of Development and Implementation & Methodology \\
\hline During HIT Design phase & - ethnography (observations, interviews) \\
& - (cognitive) task and workflow analysis and modeling \\
- heuristic evaluation with a focus on safety
\end{tabular}

enforcement of harmonized standards IEC 62366:2007, IEC 60601-16:2004, 2007 \& 2010 [19-21]

- Identify and eventually standardize, for each type of HIT tool or group of functions, safety-critical usability features or design principles that should be complied with.

- Examples: Handbook of requirements for health data display published by the Australian standards organization [55]

- Microsoft and NHS Common User Interface initiative which proposes a portfolio of standards and guidance relating to the design of user interfaces for HIT products with the objective of reducing use errors [56]

- Enhanced oversight of HIT by supporting the monitoring and reporting of incidents and errors induced by the technology.

- Example: efforts of IOM to encourage reports of users experience [57] and the resulting recent initiative by the ONC for a "Health IT Patient Safety Action and Surveillance Plan" [58]

- Integrate HF / usability methods, concepts and guidelines within procedures aiming at certifying the quality of a HIT product.

- Example: integration of a minimum usability assessment into the EHR certification criteria in the US [59] and recommendation by NIST for a HCD process for EHR technology [38]

- Development of a safety-oriented culture in organizations that develop, implement and monitor HIT, where reporting and solving safety issues involving health information systems is the focus.

- Example: Canada's Health Informatics Association is developing a eHealth Safety program that focuses on education and awareness among those involved in the HIT and health care industry, development of standards and guidelines, and monitoring and reporting [60].

In the following section we briefly describe initiatives in Europe, Canada and the US regarding HIT usability and highlight their impact on HF research in HIT. 


\subsection{Example of the Revised European Medical Device Directive}

The revised Directive 2007/47/EC [9] was published in 2007 and put into use and enforced in March 2010. The revision includes two major changes of relevance to HF for HIT.

\subsubsection{Usability as an Essential Requirement for CE Marking}

Usability is now explicitly mentioned as an essential requirement for $\mathrm{CE}$ marking to secure patient safety (along with the safety of the system's users). According to the revised Directive "it is necessary to expressly set out the need to consider ergonomic design in the essential requirements. In addition the level of training and knowledge of the user, such as in the case of a lay user, should be further emphasized within the essential requirements. The manufacturer should place particular emphasis on the consequences of misuse of the product and its adverse effects on the human body." This means that the design of a Medical Device (MD) must integrate a usability engineering process as part of the existing Risk Management process; this implies a clear focus on the risk of use errors and their prevention. To achieve this goal the manufacturer is supposed to adopt a HCD approach, and to document it. The resulting "usability file" has to be checked for conformity by certification bodies delivering CE marking. Mandated standards IEC 62366:2007, IEC 60601-1-6: 2007 \& 2010 [19-21] describe how to apply the HCD to MD and provide instructions for documentation. As they are harmonized with the revised MDD, compliance with these standards is considered compliance with the MDD.

\subsubsection{Software Considered as Medical Devices}

A number of safety-critical software are now considered medical devices, including stand alone software contributing to diagnosis or treatment (e.g., Computer Clinical Decision Support Systems). According to the revised MDD, a MD is "any instrument, apparatus, appliance, software, material or other article, whether used alone or in combination, including software intended by its manufacturer to be used specifically for diagnostic and/or therapeutic purposes and necessary for its proper application". Such types of software are considered MD [61] and therefore need CE marking to be allowed to be marketed and put into use. This opens interesting opportunities of reimbursement from National Health Insurance (in France), in case a vendor decides to go through the required additional steps such as clinical trials that demonstrate the safety and potential benefit of the new MD-software. This process will allow the vendor to get its technology registered on the list of products and services qualifying for reimbursement.

\subsubsection{Impact for HIT HF Studies}

Enforcement of the revised MDD has provoked a significantly increased demand for consultancy regarding the documentation of the usability file (and to perform usability validation and evaluation) by a number of manufacturers, including HIT vendors. Within each project led by the French authors of this chapter, there was an opportunity to investigate manufacturers' difficulties with the new critical requirements and harmonized standards [62]. Manufacturers (a generic term to refer to stakeholders and people in charge of building and documenting the CE marking file for the MD) have a poor understanding of the concept of usability. They are often unable to identify incident reports or users' negative feedback on their MD as a "use error" caused by "usability flaws" of the Human-Machine Interface (HMI). Misunderstanding the true nature and etiology of use errors, they also miss the raison d'être of the MDD essential requirement, i.e. to prevent use errors through improvement of the product itself but also its HMI. Additionally, the workload of usability engineering tasks is often underestimated and manufacturers have difficulties budgeting these tasks. One consequence of this situation is that health authorities, certification bodies and manufacturers themselves acknowledge the necessity to systematically involve HF/usability experts in the usability engineering process and documentation of the usability file.
Moreover, the standards supposed to guide the safety oriented HCD and the documentation of the usability file [19-21] are poorly written, ill-structured and require sound $\mathrm{HF} /$ usability expertise as well as knowledge of risk management to be properly understood and applied. Although both standards refer to $\mathrm{HCD}$, it is challenging to properly assign each step of the IEC standards to its proper HCD phase as described in the ISO 9241-210; this is clear when comparing figure 2 with figure 1 .

The HCD phase labeled "understand and specify the context of use" includes the first five steps of the IEC 62366:2007 standard, namely "application specification", "frequently used functions", "characteristics related to safety", "known and foreseeable hazards and hazardous situations" and "primary operating functions". The HCD phase "specify users" requirements" in ISO 9241210 corresponds to the IEC 62366:2007 standard step "usability specification", while the HCD phase "produce design solutions to meet users requirements" is referred to in IEC 62366 as "user interface design and implementation". Finally the ISO 9241-210 last phase of HCD "evaluate the design against requirements" is distributed across the IEC 62366 three steps of "usability validation plan", "usability verification" and "usability validation".

The most difficult (and confusing) part of the usability engineering process as described in the IEC 62366 standard is without doubt the one corresponding to the analysis of the context of use. The description and analysis of the context of use cannot be simply summarized by the documentation of "application specification" and "frequently used functions". The identification of the "characteristics related to safety (of use)" therefore relies on HF experts' understanding of the context of use, including collaborative aspects of the tasks, and of the true nature of users' interaction with the system. The standard also requires documenting "known or foreseeable hazards and hazardous situations". This task requires access to reports of past incidents or errors with similar MDs. Moreover manufacturers are supposed to publish an objective information about the trade-offs between safety, benefit and harm of their MD. But they consider knowledge 


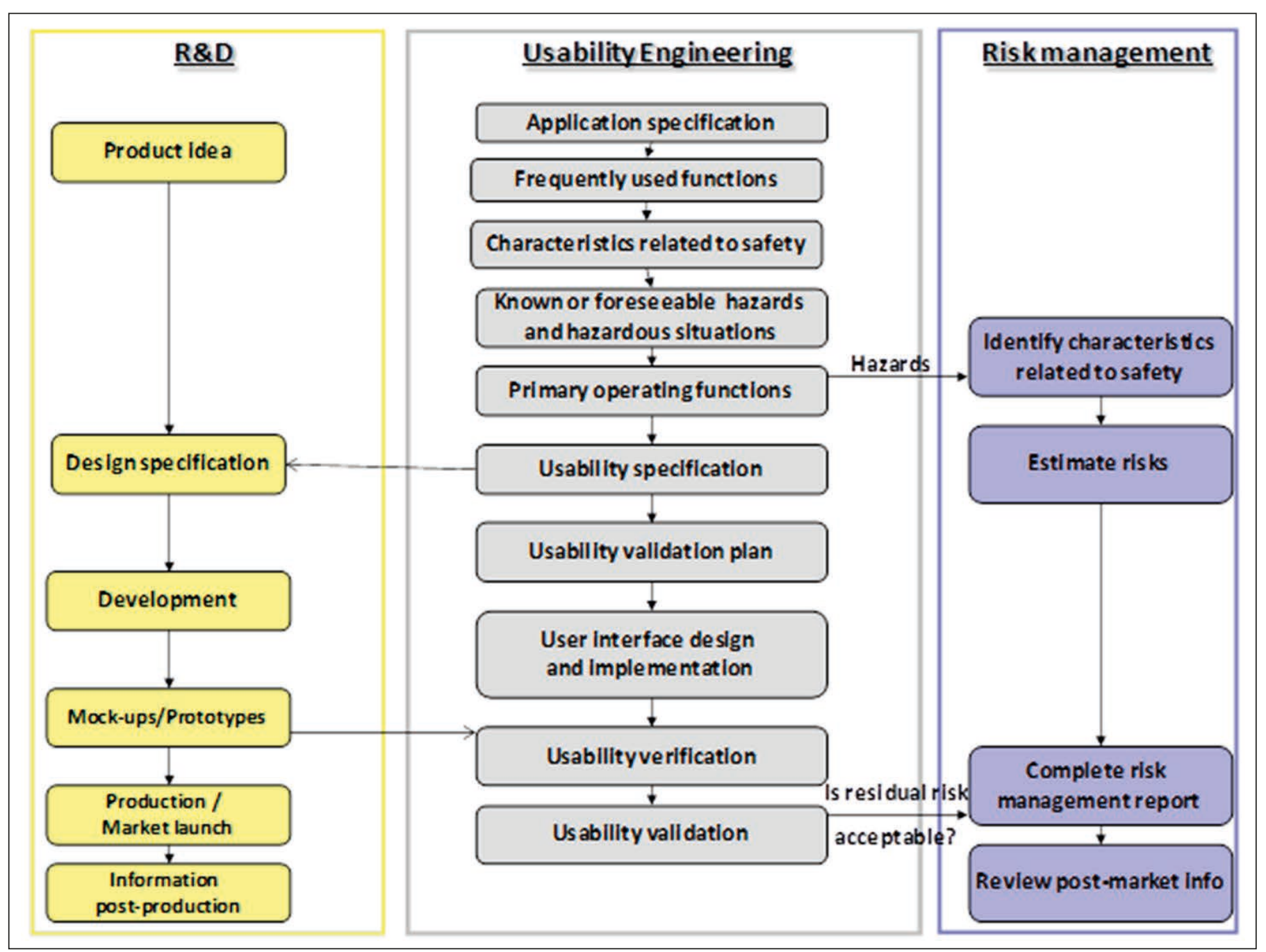

Fig. 2 List of usability engineering tasks and their relations to the R\&D and Risk management processes according to the IEC 62366:2007. The usability file is supposed to document how each task has been carried out (method) and what are the corresponding results.

about the design of their MD, especially drawbacks and glitches, as confidential. Not sharing software problems is an industry implicit norm to keep competitors at bay; this is true in many countries [63].

\subsection{Example of the Health Canada Directive: Software Regulated as a Medical Device}

In Canada two organizations are involved in the regulation and certification of healthcare software: Canada Health Infoway and Health Canada. Canada Health Infoway is involved in projects related to electronic health records and works with the provinces and territories in Canada to facilitate the adoption and use of HIT [31]. Canada Health Infoway provides federal level certification services where health information systems privacy, security, interoperability and management are concerned (not safety) [64]. Health Canada's Therapeutic Products Directorate is responsible for regulating the "advertising, manufacture and sale of medical devices in Canada" through the "Food and Drugs Act" and "Medical Devices Regulations". In 2011, Health Canada began to regulate software (e.g. electronic medical records) as medical devices. The approach is based on elements from the EU (i.e. risk-based classification system and quality system requirement) and the US FDA (i.e. post-market and pre-market licensing) regulatory systems [37].

According to Health Canada, "software is regulated as a medical device" when it "provides the only means and opportunity to capture or acquire data from a medical device for aiding directly in the diagnosis or treatment of a patient" or "replaces a diagnostic or treatment decision made by a physician" [37]. Health Canada has four classes of medical devices (i.e. I to IV). Class I devices are the lowest in risk whereas class IV devices are the highest. Class I devices can be used to view images and other data in real time "for the purpose of aiding in 
treatment and diagnosis of a patient". Class II devices include "medical device software that is an adjunct to another medical device and is involved in data manipulation, data analysis, data editing, image generation, determination of measurements, identifications of a region of interest in an image, or identification (by an alarm or alert) of results from a monitor that are outside of an established range". Class II devices could include electronic medical records [37].

To sell or import a Class I device, manufacturers, importers and distributors need to employ a licensed importer (or distributor) or they require an Establishment License. In Establishment Licensing, manufacturers are responsible to ensure devices sold in Canada comply with medical device regulations [37]. To sell or import a Class II device in Canada, a manufacturer must also obtain a License. This involves submitting an application, paying a fee and providing a copy of a valid ISO 13485:2003 quality system certificate. Manufacturers also need to apply for an amendment if the device has been changed. The License is renewed annually [37]. To date, several electronic medical record manufacturers have applied for and successfully obtained a Class II license [65]. ISO 13485:2003 focuses on promoting regulatory requirements, controls in the workplace and risk management, and has a few references to usability [66]. Health Canada is also responsible for other regulatory aspects of medical devices, including mandatory problem reports, recalls, handling of complaints, investigative testing involving human trials and special access [37]. The amount of information about how an organization demonstrates the usability of a medical device is limited.

\subsection{Examples of US Initiatives for HIT Usability}

In the US, several federal agencies and professional organizations have initiated programs targeted at HF and usability of HIT. The Agency for Healthcare Research and Quality (AHRQ) has provided support to HIT research and dissemination, including in the areas of HF and usability of EHR [63], HF of clinical decision support [67, 68], usability and workflow integration of
HIT, in particular in ambulatory care [69], and $\mathrm{HF}$ in the design of consumer health IT [70]. Research sponsored by AHRQ has described practices used by HIT vendors for EHR usability [63]. Whereas HIT vendors recognize the importance of HF and usability and report to be committed to producing usable EHR products, they use very limited and weak practices for usability and HCD. They seem to lack the personnel resources and expertise in usability engineering. In addition, as indicated earlier, vendors tend to view usability as a competitive factor and are, therefore, reluctant to share best practices and data on EHR-related problems.

The Office of the National Coordinator for Health Information Technology (ONC) has supported the work conducted by the Institute of Medicine (IOM) on health IT and patient safety [33]. As a follow-up to the IOM report on health IT and patient safety, the ONC has recently issued the Health IT Patient Safety Action and Surveillance Plan for public comment [58]. This plan is focused on patient safety issues of HIT, but gives major attention to HF issues, such as design of HIT interfaces and workflow integration. This plan clearly outlines the critical role of usability in the design of safe HIT products: "The safety of EHR developer products and services can be improved by encouraging the development and adoption of recognized industry standards for usability and quality management processes can further ensure." (page 17).

NIST is another federal agency that has significantly invested efforts and resources in HIT usability by creating a number of guidance documents on EHR usability. For instance, Schumacher and Lowry [38] describe methods and processes for enhancing the usability of EHR technology. In this report, the recommended HCD process includes an iterative flow of the following activities:

- Understand user needs, workflows and work environments

- Engage users early and often

- Set user performance objectives

- Design the user interface from known human behavior principles and familiar user interface models

- Conduct usability tests to measure how well the interface meets user needs
- Adapt the design and iteratively test with users until performance objectives are met. NIST has also issued guidance documents regarding unique $\mathrm{HF}$ and usability challenges for specific patient populations, such as children [71].

The two major professional associations related to HIT, the Healthcare Information and Management Systems Society (HIMSS) and the American Medical Informatics Association (AMIA), have also contributed to increasing the awareness of HF and usability of HIT. For instance, in 2012, the HIMSS EHR Usability Task Force issued usability guidelines to be used by small- and medium-sized practices when selecting an EHR [72]. Recently, AMIA created a task force on EHR usability and published preliminary results and recommendations [73].

\section{Persistent Challenges}

The analysis of recent safety initiatives and regulations regarding HIT usability highlights several points of interest:

- The frontier between HIT and Medical Devices is blurred; as a consequence, safety initiatives or regulations applicable to MD, including those specific to $\mathrm{HF} /$ Usability, tend to extend to HIT

- Usability is considered a fundamental dimension of HIT safety

- HF/Usability methods and the overall HCD methodology are considered efficient solutions to ensure the design and development of safe and usable HIT

However, it appears that MD manufacturers, and a fortiori HIT designers and developers are still far from being able to routinely apply the HCD to their products. Difficulties are of various nature and some of them pose interesting research challenges.

\subsection{Manufacturer's Difficulties with the Application of the HCD}

The standards supposed to guide manufacturers in this process, e.g. IEC 62366:2007 and 60601-1-6:2004, $2007 \& 2010$ [19-21] are not usable by non HF experts, and some 
parts remain unclear even for ergonomists. Additionally, the usability maturity level of manufacturers and companies is often poor [74] and not all companies have access to HF expertise to handle the HCD management of their products. This situation impedes the proper planning, budgeting and running of HCD tasks.

On the research side, we need to analyze and better understand manufacturers' difficulties with the application of the HCD process and compliance with imposed standards $[62 ; 75]$. This analysis is necessary to understand actual barriers, beyond manufacturers' mere reluctance towards new regulations. We also need to analyze systematically the format and content of standards to identify confusing and unclear sections. The combination of both analyses would help draft efficient guidance documents, documentation templates, illustrative case studies etc. It would also help identifying clearly when and how HF expertise is needed.

On the practical/organizational side, we need to make the HF expertise and guidance more visible and accessible to manufacturers and to support all forms of education and training of stakeholders in HF for HIT and MD. Combination/integration of usability studies with preclinical studies and eventually certification procedures also offers interesting perspectives. In a previous paper [1], we advocated the need for Clinical Centers for HF/Usability of Health (Information) Technologies, this still holds true in a context where manufacturers seek support to comply with new regulations and safety expectations. In this context, the French government initiative to create and support several (eight) Clinical Investigation Centers for Innovative Technologies - CIC-IT [76] is promising and starts to show interesting results, including for HF support to HIT industry and medical devices manufacturers. For instance the CICIT network has initiated and will coordinate the upcoming European project ITECH which aims at optimizing research \& innovation and transfer products and services in HIT. This project includes a section devoted to HF issues and the role of HF in the innovation to market process. This project will provide an opportunity to better identify manufacturers' and HIT vendors' difficulties with the necessary application of the HCD and try to find methods and tools to overcome the problems at a European and international level.

\subsection{Difficulties with the Analysis and Description of the "Context of Use"}

Most of the papers addressing the application of HCD to HIT and MD focus on the last phase, i.e. "Evaluate the design against requirements". Those papers report usability evaluation studies of products at various stages of their development and implementation. As highlighted in table 1, we dispose for these studies of reliable and quasi harmonized methods. The benefits of these methods in preventing use errors is also established [10,48].

We have less papers and reports on the first phase of the HCD, i.e. the understanding of the context of use [77]. This phase indeed, which is critical in terms of usability, safety and utility of the product under design and development is often underestimated and poses fundamental research challenges.

The understanding of the "context of use" relies mostly on ethnographic methods (see table 1) and requires HF expertise to be properly carried out. On site observation and interviews of the users help HF experts understand users' tasks, activities, workflows, mental processes, communication and cooperation procedures etc. and to identify foreseeable usability-related risks. This work provides the basis for usability specifications. However, given the richness and multidimensional characteristics of such data, the description and modeling of the context of use remains difficult to document. This difficulty and the numerous formats of description make hazardous the comparison of descriptions and analyses of the contexts of use for similar products.

In terms of research we need to improve our capacity to identify, for a given category of HIT system or product (e.g. medication CDSS, BCMA, medication CPOE, Laboratory Information System - LIS, etc.) the fundamental dimensions of the "context of use" (tasks, cognitive processes etc.) that would hold whatever the workplace and the organization, and that are important in terms of patient safety and use errors. Descriptions or formalizations of these analyses should be re-usable for other projects targeting the same type of tool. To carry out safety oriented analyses of the context of use it is also necessary to complement the ethnography methods with a review of reported / published HF/usability related incidents or accidents with similar applications or devices. Such specific information is not readily available. However recent research work on databases of patient safety incidents [27,28] demonstrated that:

- The databases investigated do host reports of computer or HIT related incidents, but in very small proportion $(0,1 \%$ to $0,2 \%)$; this percentage is expected to grow in the future

- A thorough secondary analysis of the reported incidents is necessary to properly identify use errors. Usability expertise is then required to link the description of these use errors to precise usability flaws of the system.

On the research side, systematic usability analysis of MD / HIT related patient safety incidents needs to be extended and refined in order to seek evidence linking usability principles - usability flaws - usage problems - negative outcomes (medical errors, patient harm). Efforts to support and organize incident reporting of HIT [78] and all forms of users' experience with HIT [57] will progressively provide interesting material for HF experts to work on.

\subsection{Challenges Related to the Reporting of Usability Studies}

Ultimately, the most important contribution to HF / Usability knowledge related to HIT comes from scientific reports of usability studies. It is therefore important that the research community may search and access good quality and well structured scientific reports of usability studies of HIT. Unfortunately, previous systematic review work on such reports has highlighted a number of problems [79].

First, system application domains (e.g. the type of system evaluated, the clinical context of use and the types of system users), system functions and features, case study objectives, stages of system development, research meth- 
ods applied, and study outcomes vary greatly across reports. An even more important problem is that these studies have been inconsistent and have not been comprehensive in their reporting. Second, the studies reviewed were incompletely described and lacked details on system functionalities, context of use, user groups, and the system development stage, $\mathrm{HF}$ methods applied, usability principles followed to give a few examples. Due to these large variations in HIT application domains, HIT features, and other study aspects and details reported on, the HIT design and usability studies were difficult to compare on their outcomes. The wide variety in the kinds of interactive healthcare applications, their contexts of use as well as the various kinds of methods applied and outcome measures defined limited the generalisability of findings, complicated the appraisal of outcomes, meta-analysis and harmonization of the available evidence. Generally, it can be concluded that the reporting of HIT design and evaluation studies is in vital need of improvement.

When the goal is to build an evidence base of sound HIT design and usability principles, reporting on these kinds of academic studies should be of a certain degree of quality: complete, homogeneous and unambiguous. The wealth of evidence in research on HIT design and usability evaluation remains under-utilized if we do not undertake efforts to standardize the reporting of these studies. There is thus a need for a framework to guide the scientific reporting of HF and usability studies of interactive healthcare technologies for ensuring high quality reporting of these studies. When scientific reports on these types of studies become consistent and complete, future HIT development projects might benefit from lessons learned concerning the methods to apply to prevent user errors, enhance user efficacy, efficiency and to reveal HIT features that may or may not contribute to safe use of a technology.

The first ideas for development of such a framework were gathered during a meeting of the IMIA WG- Human Factors Engineering for Health Informatics at the MEDINFO conference 2010. The IMIA WG acknowledged that without a framework providing guidance of the reporting of HIT design and usability evaluation studies, the building of a proper evidence base of usability and design principles of HIT that lead to safe and efficient use in practice would remain hampered. In a collaborative effort of the IMIA WG - Human Factors Engineering for Health Informatics and the EFMI WG - Human and Organizational Factors of Medical Informatics, the Dutch and French authors of this paper therefore set out to develop a framework of good practice of reporting on HIT design, development and usability studies. The framework will provide a set of principles to follow for comprehensive and unambiguous reporting of HIT design and usability evaluation studies with the objective to reduce variation and improve on the publication reporting quality of these studies. The principles are inspired by the literature on HIT design and usability studies, standards on human-centered design activities of computer-based interactive systems and existing experience of the IMIA and EFMI WGs members. The first version of the framework has been developed in an iterative process and pilot-testing phase involving experts from the HF and usability domains for HIT of the IMIA and EFMI WGs [80]. The next step is reaching international consensus on the framework by an international Delphi-study among the HF and usability experts in the health informatics community.

\subsection{Toward Usability Design Principles for HIT Applications}

We also need to make progress in the identification of essential HF / Usability features or principles that are either desirable for a given type of software or on the contrary need to be definitely banned from the design. For instance, interesting research work is going on to identify key usability principles for medication related CDSS, based on expert consensus [81-84] or fundamental cognitive research [85].

\section{Conclusion}

In line with recent position papers advocating for more and better HF / usability research for HIT [73], the present survey paper has highlighted the impact of regu- lation and patient safety initiatives in this domain, and shown that similar approaches have been adopted by the EU and North America (Canada and US). HF and usability research and studies have demonstrated their importance and their impact on the quality of care and patient safety. Indeed they appear today as a key to getting all expected benefits and promises from innovative HIT. Usable IT systems do improve patient care. Unusable and poorly designed systems are, at best, not used and therefore useless, or at worst they may generate poor performance and technology-induced errors. Throughout the world there is a need for regulatory bodies to promote Human Centered Design of Medical Devices and HIT. Research teams working in this domain must continue to explore all dimensions of system-user interactions and support the evolution of regulations, e.g. by improving the quality of harmonized standards. HF research and academic teams also have a role in disseminating this knowledge amongst students, searchers, stakeholders, companies, and healthcare professionals to improve the quality and the usability of future HIT applications.

\section{References}

1. Beuscart-Zephir MC, Elkin P, Pelayo S, Beuscart $R$. The human factors engineering approach to biomedical informatics projects: state of the art, results, benefits and challenges. Yearb Med Inform 2007;109-27.

2. Beuscart-Zephir MC, Pelayo S, Borycki E, Kushniruk A. Human Factors Considerations in Health IT Design and Development. In: Carayon P, editor. Human Factors and Ergonomics in Health Care and Patient Safety $2^{\text {nd }}$ Edition. CRC Press; 2012. p. 649-70.

3. To Err Is Human: Building a Safer Health System. The National Academies Press; 2000.

4. Blumenthal D, Tavenner M. The "meaningful use" regulation for electronic health records. N Engl J Med 2010 Aug 5;363(6):501-4.

5. Meaningful Use. Health IT gov 2013 [cited 2013 Jan 12]; Available from: URL: http://www. healthit.gov/policy-researchers-implementers/ meaningful-use

6. Stringer J, Sinkala M, Fuller J. US-Zambian Collaboration Receives \$4 Million To Establish Electronic Obstetric And Newborn Medical Record In Lusaka, Zambia. Gates Foundation 2001 July 11 [cited 2013 Jan 12];Available from: URL: http://www.gatesfoundation.org

7. Borycki E, Kushniruk A. Where do technology-induced errors come from? Towards a model for 
conceptuallizing and diagnosing errors caused by technology. In: Kushniruk A, Borycki E, editors. Human, Social and Organizational Aspects of Health Information Systems. Hershey, NY, Idea Group; 2008.

8. Wetterneck TB, Walker JM, Blosky MA, Cartmill RS, Hoonakker P, Johnson MA, et al. Factors contributing to an increase in duplicate medication order errors after CPOE implementation. J Am Med Inform Assoc 2011 Nov;18(6):774-82.

9. Directive 2007/47/EC of the European Parliament and of the Council. Official Journal of the European Union 2007 September 5 [cited 2013 Jan 12]; Available from: URL: http://eur-lex.europa.eu/

10. Borycki E, Kushniruk A. Identifying and preventing technology-induced error using simulations: application of usability engineering techniques. Healthc Q 2005;8 Spec No:99-105.

11. Kushniruk AW, Triola MM, Borycki EM, Stein B, Kannry JL. Technology induced error and usability: the relationship between usability problems and prescription errors when using a handheld application. Int J Med Inform 2005 Aug;74(78):519-26

12. Karsh BT, Weinger MB, Abbott PA, Wears RL. Health information technology: fallacies and sober realities. J Am Med Inform Assoc 2010 Nov;17(6):617-23.

13. International Ergonomics Association. Definition of Ergonomics. International Ergonomics Association 2012 February 20 [cited 2013 Jan 12];Available from: URL: http://www.iea.cc/

14. International Organization for Standardization. Ergonomics of human-system interaction - Part 210: Human-centred design for interactive systems. Geneva: International Organization for Standardization; 2010.

15. Horsky J, Kuperman GJ, Patel VL. Comprehensive analysis of a medication dosing error related to CPOE. J Am Med Inform Assoc 2005 Jul;12(4):377-82.

16. Patel VL, Currie LM. Health IT Patient Safety Action and Surveillance Plan. Int J Med Inform 2005 Dec;74(11-12):869-85.

17. Carayon P, Hundt AS. Work system design for patient safety: The SEIPS model. Quality and Safety in Health Care 2006;15(Supplement I):i50-i58.

18. Ammenwerth E, Schnell-Inderst P, Machan C, Siebert U. The effect of electronic prescribing on medication errors and adverse drug events: a systematic review. J Am Med Inform Assoc 2008 Sep;15(5):585-600.

19. International Electrotechnical Commission. Application of usability engineering to medical devices. Geneva: International Electrotechnical Commission; 2007. Report No.: IEC 62366.

20. International Electrotechnical Commission. Medical Electrical Equipment - General requirements for basic safety and essential performance. Collateral Standard. Usability. Geneva: International Electrotechnical Commission; 2007. Report No.: IEC 60601-1-6).

21. International Electrotechnical Commission. Medical Electrical Equipment - General requirements for basic safety and essential performance. Collateral Standard. Usability. Geneva: International Electrotechnical Commission; 2010. Report No.:
IEC 60601-1-6.

22. Walker JM, Carayon P, Leveson N, Paulus RA, Tooker J, Chin H, et al. EHR safety: the way forward to safe and effective systems. J Am Med Inform Assoc 2008 May;15(3):272-7.

23. Borycki EM, Househ MS, Kushniruk AW, Nohr C, Takeda H. Empowering Patients: Making Health Information and Systems Safer for Patients and the Public. Contribution of the IMIA Health Informatics for Patient Safety Working Group. Yearb Med Inform 2012;7(1):56-64.

24. Kushniruk A, Borycki E, Kuwata S, Kannry J. Predicting changes in workflow resulting from healthcare information systems: ensuring the safety of healthcare. Healthc Q 2006 Oct;9 Spec No:114-8.

25. Peute LW, Jaspers MW. The significance of a usability evaluation of an emerging laboratory order entry system. Int J Med Inform 2007 Feb;76(23):157-68.

26. Khajouei R, Peek N, Wierenga PC, Kersten MJ, Jaspers MW. Effect of predefined order sets and usability problems on efficiency of computerized medication ordering. Int J Med Inform 2010 Oct;79(10):690-8.

27. Magrabi F, Ong MS, Runciman W, Coiera E. An analysis of computer-related patient safety incidents to inform the development of a classification. J Am Med Inform Assoc 2010 Nov; 17(6):663-70.

28. Magrabi F, Ong MS, Runciman W, Coiera E. Using FDA reports to inform a classification for health information technology safety problems. J Am Med Inform Assoc 2012 Jan;19(1):45-53.

29. Campbell EM, Sittig DF, Ash JS, Guappone KP, Dykstra RH. Types of unintended consequences related to computerized provider order entry. J Am Med Inform Assoc 2006 Sep;13(5):547-56.

30. Koppel R, Metlay JP, Cohen A, Abaluck B, Localio AR, Kimmel SE, et al. Role of computerized physician order entry systems in facilitating medication errors. JAMA 2005 Mar 9;293(10):1197-203.

31. What we do. Canada Health Infoway 2012 [cited 2013 Jan 12]; Available from: URL: https://www. infoway-inforoute.ca/index.php/about-infoway/ what-we-do

32. Olin J. Technology induced errors a new RN concern. RN Central 2012 May 29 [cited 2013 Jan 12]; Available from: URL: http://www. rncentral.com

33. Institute Of Medicine. Health IT and Patient Safety: Building Safer Systems for Better Care. The National Academic Press, Washington DC; 2012.

34. Computational Technology for Effective Health Care:Immediate Steps and Strategic Directions. The National Academies Press; 2009.

35. Borycki EM, Kushniruk AW, Kuwata S, Kannry J. Engineering the electronic health record for safety: a multi-level video-based approach to diagnosing and preventing technology-induced error arising from usability problems. Stud Health Technol Inform 2011;166:197-205.

36. Borycki E, Keay E. Methods to assess the safety of health information systems. Healthc Q 2010 Sep;13 Spec No:47-52.

37. Software regulated as medical device. Health Canada 2010 December 3 [cited 2013 Jan 12]; Available from: URL: http://www.hc-sc.gc.ca/

38. Schumacher RM, Lowry SZ. NIST Guide to the
Processes Approach for Improving the Usability of Electronic Health Records. US National Institute of Standards and Technology; 2010 Nov. Report No.: NISTIR 7741

39. Patel VL, Kushniruk AW, Yang S, Yale JF. Impact of a computer-based patient record system on data collection, knowledge organization, and reasoning. J Am Med Inform Assoc 2000 Nov;7(6):569-85.

40. Ash JS, Berg M, Coiera E. Some unintended consequences of information technology in health care: the nature of patient care information system-related errors. J Am Med Inform Assoc 2004 Mar;11(2):104-12.

41. Cheng CH, Goldstein MK, Geller E, Levitt RE. The Effects of CPOE on ICU workflow: an observational study. AMIA Annu Symp Proc 2003;150-4.

42. Beuscart-Zephir MC, Anceaux F, Menu H, Guerlinger S, Watbled L, Evrard F. User-centred, multidimensional assessment method of Clinical Information Systems: a case-study in anaesthesiology. Int J Med Inform 2005 Mar; 74(2-4):179-89.

43. Ash JS, Sittig DF, Poon EG, Guappone K, Campbell E, Dykstra RH. The extent and importance of unintended consequences related to computerized provider order entry. J Am Med Inform Assoc 2007 Jul;14(4):415-23.

44. Koppel R, Wetterneck T, Telles JL, Karsh BT. Workarounds to barcode medication administration systems: their occurrences, causes, and threats to patient safety. J Am Med Inform Assoc 2008 Jul;15(4):408-23.

45. Patterson ES, Cook RI, Render ML. Improving patient safety by identifying side effects from introducing bar coding in medication administration. J Am Med Inform Assoc 2002 Sep;9(5):540-53.

46. Magrabi F, Ong MS, Runciman W, Coiera E. Patient safety problems associated with heathcare information technology: an analysis of adverse events reported to the US Food and Drug Administration. AMIA Annu Symp Proc 2011;2011:853-7.

47. Jaspers MW. A comparison of usability methods for testing interactive health technologies: methodological aspects and empirical evidence. Int J Med Inform 2009 May;78(5):340-53.

48. Borycki EM, Kushniruk A, Keay E, Nicoll J, Anderson J, Anderson M. Toward an integrated simulation approach for predicting and preventing technology-induced errors in healthcare: implications for healthcare decision-makers. Healthc Q 2009;12 Spec No Patient:90-6.

49. Marcilly R, Bernonville S, Riccioli C, Beuscart-Zephir MC. Patient safety-oriented usability testing: a pilot study. Stud Health Technol Inform 2012;180:368-72.

50. Kushniruk A, Beuscart-Zephir MC, Grzes A, Borycki E, Watbled L, Kannry J. Increasing the safety of healthcare information systems through improved procurement: toward a framework for selection of safe healthcare systems. Healthc Q 2010 Sep;13 Spec No:53-8.

51. Ash JS, Sittig DF, McMullen CK, Guappone K, Dykstra R, Carpenter J. A rapid assessment process for clinical informatics interventions. AMIA Annu Symp Proc 2008;26-30.

52. Rule AM, Drincic A, Galt KA. New technology, new errors: how to prime an upgrade of an insulin infusion pump. Jt Comm J Qual Patient Saf 2007 Mar;33(3):155-62. 
53. Kushniruk AW, Kaufman DR, Patel VL, Levesque Y, Lottin P. Assessment of a computerized patient record system: a cognitive approach to evaluating medical technology. MD Comput 1996 Sep;13(5):406-15.

54. Magrabi F, Aarts J, Nohr C, Baker M, Harrison S, Pelayo S, et al. A comparative review of patient safety initiatives for national health information technology. Int J Med Inform 2012 Dec 18.

55. User interface requirements for the presentation of health data. Standards Australia; 2007 Dec 31. Report No.: HB 306-2007.

56. Common User interface (CUI). NHS Connecting for Health 2013 [cited 2013 Jan 12]; Available from: URL: http://www.connectingforhealth.nhs. uk/systemsandservices/data/cui

57. Sinsky CA, Hess J, Karsh BT, Keller JP, Koppel R. Comparative User Experiences of Health IT Products: How User Experiences Would Be Reported and Used. Discussion Paper, Institute Of Medicine 2012 SeptemberAvailable from: URL: http://www.iom.edu/Global/Perspectives/2012/ ComparativeUserExperienceHIT.aspx.

58. Health IT Patient Safety Action and Surveillance Plan for Public Comment. ONC (Office of the National Coordinator for Health Information Technology 2012 December 21 [cited 2013 Jan 12]; Available from: URL: http://www.healthit.gov/

59. CCHIT 2011 Usability Testing Guide for Ambulatory EHR's. CCHIT (Certification Commission for Health Information Technology) 1009 February [cited 2013 Jan 12]; Available from: URL:https:// www.cchit.org/ambulatory-ehr/

60. Gardner N, Keller E. eHealth Safety - A Journey Begun... An Action Needed... \& A Program Under Development. Canada's Health Informatics Association 2012 May 1 [cited 2013 Jan 12]; Available from: URL: http://www.coachorg.com/

61. Guidelines on the qualification and classification of stand alone software used in healthcare within the regulatory framework of medical devices. European Commission DG Health and Consumer 112 [cited 2013 Jan 12]; Available from: URL: http://ec.europa.eu/

62. Bras Da Costa S, Pelayo S, Bastien C, Beuscart-Zephir MC. Issues in the implementation of the ISO 62366:2007 standard for medical devices' usability and safety: a case study.: CRC Press; 2011.

63. Mc Donnell C, Werner K, Wendel L. Electronic Health Record Usability: Vendor Practices and Perspectives. Rockville, MD: Agency for Healthcare Research and Quality; 2010 May. Report No.: AHRQ Publication No. 09(10)-0091-3-EF.

64. Certification services. Canada Health Infoway 2012 [cited 2013 Dec 1]; Available from: URL: https://www.infoway-inforoute.ca/index.php/ programs-services/certification-services

65. 2010 directory of healthcare IT suppliers. Canadian Healthcare Technology 2013 [cited 2013 Jan 12];Available from: URL: http://www.canhealth. $\mathrm{com} /$ direct10.html

66. Medical devices -- Quality management systems -- Requirements for regulatory purposes. International Organization for Standardization; 2003. Report No.: ISO 1385-2003.

67. Karsh BT. Clinical practice improvement and redesign: How change in workflow can be supported by clinical decision support. Rockville, Maryland: Agency for Healthcare Research and Quality; 2009. Report No.: AHRQ publication $\mathrm{N}^{\circ}$ 09-0054-EF.

68. Berner ES. Clinical Decision Support Systems: State of the Art. 2009 Jun. Report No.: AHRQ Publication No. 09-0069-EF.

69. Carayon P, Karsh BT. Incorporating Health Information Technology into Workflow Redesign-Summary Report. Rockville, MD: Agency for Healthcare Research and Quality; 2010 Oct. Report No.: 10-0098-EF.

70. Agarwal R, Anderson C, Crowley K, Kannan PK. Improving Consumer Health IT Application Development: Lessons From Other Industries - Background Report. Rockville, MD: Agency for Healthcare Research and Quality; 2011 May. Report No.: 11-0065-EF

71. Lowry SZ, Quinn MT, Ramaiah M, Brick D, Patterson E, Zhang J, et al. A Human Factors Guide to Enhance EHR Usability of Critical User Interactions when Supporting Pediatric Patient Care. NIST (National institute of standards and Technology); 2012 Jun. Report No.: NIST.IR.7865.

72. HIMSS EHR Usability Task Force. Selecting an EHR for Your Practice: Evaluating Usability. 2010.

73. Middleton B, Bloomrosen M, Dente MA, Hashmat B, Koppel R, Overhage JM, et al. Enhancing patient safety and quality of care by improving the usability of electronic health record systems: recommendations from AMIA. J Am Med Inform Assoc 2013 Jan 25.

74. Jokela T. Evaluating the user-centredness of development organisations: conclusions and implications from empirical usability apability maturity assessments. Interacting with Computers 2004;16(6):1095-132.

75. van der PJ, Klein J, Grass C, Freudenthal A. Design for risk control: the role of usability engineering in the management of use-related risks. J Biomed Inform 2012 Aug;45(4):795-812.

76. The CIC-IT network. http://www.cic-it fr/en/index php 2013 [cited 2013 May 10];

77. Beuscart-Zephir MC, Pelayo S, Bernonville S. Ex- ample of a Human Factors Engineering approach to a medication administration work system: potential impact on patient safety. Int J Med Inform 2010 Apr;79(4):e43-e57.

78. AHRQ common formats. AHRQ PSO (Patient Safety Organisations) Website 2013 January [cited 2013 Jan 12]; Available from: URL: https://www. psoppc.org/web/patientsafety/commonformats

79. Peute LW, Spithoven R, Bakker PJ, Jaspers MW. Usability studies on interactive health information systems; where do we stand? Stud Health Technol Inform 2008;136:327-32.

80. Peute LW, Driest KF, Marcilly R, Bras Da Costa S, Beuscart-Zephir MC, Jaspers MW. A framework for reporting on Human Factor / Usability studies of Health Information Technologies. Stud Health Technol Inform. In press 2013.

81. Bates DW, Kuperman GJ, Wang S, Gandhi T, Kittler A, Volk L, et al. Ten commandments for effective clinical decision support: making the practice of evidence-based medicine a reality. J Am Med Inform Assoc 2003 Nov; 10(6):523-30.

82. Phansalkar S, Edworthy J, Hellier E, Seger DL, Schedlbauer A, Avery AJ, et al. A review of human factors principles for the design and implementation of medication safety alerts in clinical information systems. J Am Med Inform Assoc 2010 Sep;17(5):493-501.

83. Sittig DF, Wright A, Osheroff JA, Middleton B, Teich JM, Ash JS, et al. Grand challenges in clinical decision support. J Biomed Inform 2008 Apr;41(2):387-92.

84. Pelayo S, Marcilly R, Bernonville S, Leroy N, Beuscart-Zephir MC. Human factors based recommendations for the design of medication related clinical decision support systems (CDSS). Stud Health Technol Inform 2011;169:412-6.

85. Horsky J, Schiff GD, Johnston D, Mercincavage L, Bell D, Middleton B. Interface design principles for usable decision support: a targeted review of best practices for clinical prescribing interventions. J Biomed Inform 2012 Dec;45(6):1202-16.

\section{Correspondence to:}

Marie-Catherine Beuscart-Zéphir

Evalab, INSERM CIC-IT Lille, CHU Lille

Parc Eurasanté, bâtiment Hippocrate

150/154 Rue du Dr Yersin

59120 Loos Cedex

Tel (office): +33 (0)3 20444883

Tel (cell): +33 (0)6 21374949

Fax: + $33(0) 320626881$

E-mail:mcbeuscart@univ-lille2.fr

http://www.univ-lille2.fr/evalab/ 